\title{
Rapid Detection of Genes Encoding Extended-Spectrum Beta-Lactamase and Carbapenemase in Clinical Escherichia coli Isolates with eazyplex SuperBug CRE System
}

\author{
Patrycja Zalas-Więcek, ${ }^{1}$ Eugenia Gospodarek-Komkowska, ${ }^{1}$ and Agata Smalczewska ${ }^{2}$
}

\begin{abstract}
Objectives: This study evaluated the diagnostic performance of the eazyplex ${ }^{\circledR}$ SuperBug CRE (eSBCRE) system, based on a loop-mediated isothermal amplification (LAMP), for the detection of the most common extended-spectrum beta-lactamases (ESBL) and carbapenemase genes in 140 clinical isolates of Escherichia coli.
\end{abstract}

Materials and Methods: ESBL (bla $a_{\mathrm{CTX}-\mathrm{M}-1 \text { group }}$ and $\left.b l a_{\mathrm{CTX}-\mathrm{M}-9 \text { group }}\right)$ and carbapenemase (bla $a_{\mathrm{KPC}}, b l a_{\mathrm{VIM}}$, $b l a_{\mathrm{NDM}}, b l a_{\mathrm{OXA}-48}$, and $\left.b l a_{\mathrm{OXA}-181}\right)$ genes were detected using the eSBCRE test and compared with the results obtained by PCR, real-time PCR, and phenotypic methods.

Results: Concordant results of 100\% between PCR/real-time PCR and eSBCRE assays were observed. Two of $140 \mathrm{E}$. coli isolates were positive for both ESBL and carbapenemase genes according to eSBCRE, PCR, and real-time PCR assays, whereas they were negative in double-disk synergy test. Of 16 E. coli isolates suspected of producing carbapenemase, 9 were positive for 48-oxacillinases (OXA-48) by $30 \mu \mathrm{g}$ temocillin test, whereas the $b a_{\text {OXA-48 }}$ was found only in $1 \mathrm{E}$. coli isolate by all molecular methods. Maximum threshold time values (minutes:seconds) in the eSBCRE test were 6:00, 11:15, 11:00, and 9:00 for the $b l a_{\mathrm{CTX}-\mathrm{M}-1 \text { group }}, b l a_{\mathrm{CTX}-\mathrm{M}-}$ 9group, $b l a_{\mathrm{VIM}}$, and $b l a_{\mathrm{OXA}-48}$ genes, respectively.

Conclusions: The eSBCRE test based on LAMP method is a reliable, easy-to-use, and timesaving molecular system, which can be successfully used in the routine diagnostic for the rapid detection of the most common ESBL and carbapenemase genes among clinical E. coli isolates.

Keywords: Escherichia coli, carbapenemases, extended-spectrum beta-lactamases, loop-mediated isothermal amplification

\section{Introduction}

$\boldsymbol{E}$ SCHERICHIA COLI IS one of the Enterobacterales known to cause many nosocomial infections, such as urinary tract infections, wound infections, intra-abdominal infections, pneumonia, bacteremia, sepsis, and neonatal meningitis. ${ }^{1}$ Multidrug-resistant (MDR), extensively drug-resistant (XDR), extended-spectrum beta-lactamase- (ESBL), and/or carbapenem-resistant (CR) E. coli strains are of particular note, because of significant limitations of antibiotic therapy. The prevalence of these kinds of strains has dramatically increased over the past years and this is a serious public health concern. ${ }^{2}$
Resistance of E. coli to beta-lactam antibiotics is attributed to the ability to produce ESBLs, mainly CTX-M type and carbapenemases: class A (serine carbapenemases, such as Klebsiella pneumoniae carbapenemase [KPC]); class B (metallo-beta-lactamases [MBL]), such as VIM (Verona integron-encoded metallo-beta-lactamase) and NDM (New Delhi metallo-beta-lactamases); and class D (oxacillinases [OXA]), such as OXA-48 type. ${ }^{2,3}$

In Poland, a high prevalence of beta-lactamase-producing and CR Gram-negative bacteria was observed. The predominant type of ESBL enzyme is CTX-M-1, which is present mainly in E. coli and K. pneumoniae, whereas the most common carbapenemases are VIM, NDM, and KPC. ${ }^{2-5}$

\footnotetext{
${ }^{1}$ Department of Microbiology, Ludwik Rydygier Collegium Medicum, Nicolaus Copernicus University, Dr Antoni Jurasz University Hospital No 1, Bydgoszcz, Poland.

${ }^{2}$ Student Research Club at Department of Microbiology, Ludwik Rydygier Collegium Medicum, Nicolaus Copernicus University, Bydgoszcz, Poland.
} 
Therefore, rapid and reliable detection of ESBLs and carbapenemases is essential not only for the initiation of an appropriate antibiotic treatment, but also for the infection control and for stopping of its spread.

A few phenotypic techniques are used for the detection of ESBLs (e.g., double-disk synergy test [DDST], Etest ESBL) and carbapenemases (Carba NP, Ethylenediaminetetraacetic acid [EDTA], boronic acid, and temocillin tests). However, these techniques are bacterial growth dependent, may take up to 48 hours, and the results obtained using these methods may be subjective, making them less clinically and epidemiologically useful. Molecular techniques are comparatively faster than phenotypic methods, more sensitive, and accurate for the detection of ESBL and carbapenemase genes.

The interest of microbiologists and clinicians in the detection of genes encoding resistance mechanisms by loopmediated isothermal amplification (LAMP), which is a rapid and simple method with a high sensitivity, has been growing recently. ${ }^{6}$ The eazyplex ${ }^{\circledR}$ SuperBug CRE (eSBCRE) tests (Amplex Biosystems $\mathrm{GmbH}$ ), adapted for the use on Genie ${ }^{\circledR}$ II device (Optigene), is a commercially available qualitative molecular assay, based on LAMP method, that detects genes encoding the predominant groups of ESBLs such as CTX-M1 and CTX-M-9, and carbapenemases such as KPC, VIM, NDM, OXA-48, and OXA-181 type, directly from blood culture medium, urine, rectal swabs, and bacterial culture. ${ }^{7-10}$

Therefore, the main objective of this study was to evaluate the performance of the eSBCRE system for the detection and identification of genes encoding the most common ESBLs and carbapenemases in clinical E. coli isolates.

\section{Materials and Methods}

\section{Bacterial isolates and identification}

The study included $140 \mathrm{E}$. coli isolates from the collection of the Department of Microbiology, Ludwik Rydygier Collegium Medicum, Nicolaus Copernicus University in Bydgoszcz (Poland). All of them were isolated from clinical samples of patients hospitalized in different clinical departments from January 2016 to August 2018 in two Polish Teaching Hospitals. E. coli isolates were derived from different clinical specimens including blood, urine, sputum, abdominal, and pleural fluids, and stool, wound, and rectal swabs. Bacteria were identified by applying mass spectrometry in the MALDI Biotyper system (Bruker), according to the manufacturer's instruction.

\section{Antimicrobial susceptibility}

Antimicrobial susceptibility testing was performed according to the European Committee on Antimicrobial Susceptibility Testing recommendations (version 9.0) ${ }^{11}$ using NMIC-402 that were read out with the Phoenix M50 automated system (Becton-Dickinson).

\section{Phenotypic screening of ESBLs and carbapenemases}

E. coli isolates were classified as ESBL producers based on their resistance to penicillins and cephalosporins, positive Phoenix M50 ESBL testing and DDST, using the following disks: ceftazidime $(30 \mu \mathrm{g})$, cefotaxime $(30 \mu \mathrm{g})$, and amoxicillin/clavulanic acid $(20 / 10 \mu \mathrm{g})$. To increase the sensitivity of the test, disks containing cefepime $(30 \mu \mathrm{g})$ were added. In the absence of susceptibility of strains, at least one of the carbapenems (i.e., imipenem, meropenem or ertapenem), Carba NP test (Bufor B-PER II, Thermo Scientific; Tienam [imipenem $500 \mathrm{mg}+$ cilastatin $500 \mathrm{mg}$ ], Merck Sharp \& Dohme; Phenol-red solution 0.5\%, Sigma Aldrich; $\mathrm{ZnSO}_{4} 7$ $\mathrm{H}_{2} \mathrm{O}$, Merck) was performed. ${ }^{12}$

To detect the type of carbapenemase, phenotypic tests, that is, EDTA test for MBL (EDTA, Sigma-Aldrich; ceftazidime $[30 \mu \mathrm{g}]$ and imipenem $[10 \mu \mathrm{g}]$, Oxoid), ${ }^{13}$ boronic acid test for KPC (boronic acid, Sigma-Aldrich; meropenem $[10 \mu \mathrm{g}]$, Oxoid) ${ }^{14}$ and $30 \mu \mathrm{g}$ temocillin test for OXA-48 (Oxoid $)^{15,16}$ were applied.

\section{$M D R, X D R$, and pan-drug-resistant \\ E. coli categorization}

E. coli isolates nonsusceptible to one or more antimicrobial agents from three or more antimicrobial classes were defined as MDR bacteria, nonsusceptible to one or more antimicrobial agents in all but two or fewer classes were defined as XDR bacteria, and nonsusceptible to all antimicrobial classes tested were defined as PDR (pan-drug resistant). ${ }^{17}$

\section{DNA extraction and PCR assay}

DNA was extracted from E. coli isolates using a Genomic Mini Purification kit (A\&A Biotechnology) according to the manufacturer's instructions. The presence of the $b l a_{\text {CTX-M }}$ gene was estimated using the PCR method previously described by Liao et al. ${ }^{18}$ The $b l a_{\mathrm{IMP}}$, $b l a_{\mathrm{VIM}}$, and $b l a_{\mathrm{OXA}-48}$ genes were detected using the method previously described by Pitout et al. ${ }^{19}$ and Poirel et al. ${ }^{20}$ The electrophoretic separation was carried out in a $1.5 \%$ agarose gel with Midori Green DNA dye (ABO) and visualized with UV light by the Gel Doc XR+ system (Bio-Rad).

\section{Real-time PCR assay}

The carbapenemase genes $\left(b l a_{\mathrm{KPC}}, b l a_{\mathrm{VIM} / \mathrm{IMP}}, b l a_{\mathrm{NDM}}\right.$, and $\left.b l a_{\text {OXA-48 }}\right)$ detection was performed with the BD MAX ${ }^{\mathrm{TM}}$ Check-Points CPO assay on the BD MAX system (BectonDickinson), according to the manufacturer's instructions.

\section{LAMP assay}

ESBL ( $b l a_{\text {CTX-M-1group }}$ and $\left.b l a_{\text {CTX-M-9group }}\right)$ and carbapenemase $\left(b l a_{\mathrm{KPC}(2-15)}, b l a_{\mathrm{VIM}(1-37)}\right.$, bla $a_{\mathrm{NDM}(1-7)}, b l a_{\mathrm{OXA}-}$ 48group(48,162,204,244), and $\left.b l a_{\text {OXA-181 }}\right)$ genes were detected using the eSBCRE test (Amplex Biosystems $\mathrm{GmbH}$ ), and read out with the Genie II device (Optigene), according to the manufacturer's instructions.

The $b l a_{\text {CTX-M }}$ gene was detected for all MDR and XDR E. coli strains, and the carbapenemase genes were detected for all $E$. coli isolates nonsusceptible to at least one of the carbapenems.

\section{Results}

\section{Antimicrobial susceptibility of $\mathrm{E}$. coli strains}

Of 140 E. coli isolates, 6 (4.3\%), 8 (5.7\%), and 17 (12.1\%) were resistant to imipenem, meropenem, and ertapenem, respectively, whereas $9(6.4 \%), 6(4.3 \%)$, and 1 $(0.7 \%)$ isolates exhibited intermediate susceptibility to 
imipenem, meropenem, and ertapenem, respectively. Seventeen $E$. coli isolates were nonsusceptible to at least one of the carbapenems (imipenem, meropenem, or ertapenem). Of $140 \mathrm{E}$. coli isolates, $93(66.4 \%)$ and $7(5.0 \%)$ were defined as MDR and XDR, respectively. None of the isolates were PDR.

\section{Detection of ESBL and carbapenemase enzymes using phenotypic methods}

Of the $140 \mathrm{E}$. coli isolates, $84(60.0 \%)$ were positive for ESBLs by DDST and Phoenix M50 ESBL method. Sixteen $(11.4 \%)$ of all isolates were positive in Carba NP test, and of these $15(93.7 \%)$ were positive for MBL by EDTA test and $9(56.2 \%)$ were positive for OXA-48 by $30 \mu \mathrm{g}$ temocillin test (Table 1). None of the E. coli isolates showed KPC by boronic acid test.

\section{PCR and real-time PCR assay}

As for the PCR assay 86, 15, and 1 of all E. coli isolates were positive for the $b l a_{\mathrm{CTX}-\mathrm{M}}, b l a_{\mathrm{VIM}}$, and $b l a_{\mathrm{OXA}-48}$ genes, respectively (Table 1 ). None of the $E$. coli isolates were positive for the $b l a_{\text {IMP }}$ gene. On the contrary, with the realtime PCR assay, 15 of the tested E. coli isolates were positive for the $b l a_{\mathrm{VIM} / \mathrm{IMP}}$ genes, and 1 isolate was positive for the $b l a_{\text {OXA-48 }}$ gene. None of the $E$. coli isolates were positive for the $b l a_{\mathrm{KPC}}$ and $b l a_{\mathrm{NDM}}$ genes.

\section{Rapid detection and identification of ESBL and carbapenemase genes using LAMP assay}

LAMP results indicated that $76(54.3 \%)$, and $10(7.1 \%)$ among $140 \mathrm{E}$. coli isolates were positive for the $b l a_{\mathrm{CTX}-\mathrm{M}}$

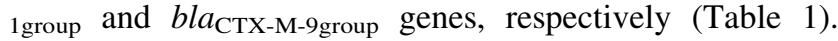
Sixteen (11.4\%) isolates were positive for carbapenem resistance determines genes. The $b l a_{\mathrm{VIM}}$ gene was the most frequent - it was detected in $15(10.7 \%) E$. coli isolates. The $b l a_{\mathrm{OXA}-48}$ gene was detected in one isolate. The $b l a_{\mathrm{KPC}}$, $b l a_{\mathrm{NDM}}$, and $b l a_{\mathrm{OXA}-181}$ genes were not detected in any of the isolates tested. Two E. coli isolates were positive for both ESBL and carbapenemase genes. One of them was positive for bla $_{\mathrm{CTX} \text {-M-9group }}$ and bla $_{\mathrm{OXA}-48}$ genes, whereas the other was positive for the $b l a_{\mathrm{CTX}-\mathrm{M}-1 \text { group }}$ and $b l a_{\mathrm{VIM}}$ genes (Table 1).

Among all E. coli isolates, invalid results were found in one sample (no. 69), in which all seven targets showed positive unspecific fluorescent signals. However, after repeating the assay with prolonged incubation ( 5 minutes instead of 2 minutes at $99^{\circ} \mathrm{C}$ ), a positive result was obtained only for the bla $a_{\mathrm{VIM}}$ gene.

The cycle threshold time for fluorescence intensity values (minutes:seconds) for beta-lactamase genes, detected by the eSBCRE test, ranged from 3:30 to 6:00 with threshold time $_{50} 4: 15$ for the CTX-M-1 group, from 5:00 to 11:15 with threshold time 50 7:30 for the CTX-M-9 group, and from 4:30 to 11:00 with threshold time 50 5:30 for VIM and 9:00 for OXA-48.

\section{Discussion}

Patients infected with XDR and MDR Enterobacterales have higher mortality rates and thus require prompt and effective treatment. ${ }^{2,21}$ Detection of ESBL and carbapenemase production is important because it facilitates adequate antimicrobial treatment of infections owing to ESBL- and carbapenemase-producing Gram-negative bacteria, which are a significant public health problem. From an epidemiological point of view, rapid detection of these bacteria with strict implementation of hygiene procedures prevents and limits their spread in a hospital environment. ${ }^{22}$

In this study, the diagnostic usefulness of the eSBCRE test based on the LAMP assay, for the rapid detection of the most common ESBL and carbapenemase genes in clinical E. coli isolates was proved. With this test, ESBL and carbapenemase genes can be detected in a short time ( $\sim 15$ minutes), from a single bacterial colony. Maximum threshold time values (minutes:seconds) were 6:00, 11:15, 11:00, and 9:00 for the bla $a_{\mathrm{CTX}-\mathrm{M}-1 \text { group }}$, bla $a_{\mathrm{CTX}-\mathrm{M}-9 \text { group }}, b l a_{\mathrm{VIM}}$, and $b l a_{\mathrm{OXA}-48}$ genes, respectively.

Furthermore, the Genie II device allows examining two isolates in parallel, which makes it a relatively high bandwidth system. In comparison, DDST, EDTA, boronic acid, and $30 \mu \mathrm{g}$ temocillin tests last for even 18-24 hours. The Carba NP test, which is a colorimetric assay, takes $\sim 2$

Table 1. Comparison of Performance Between: eazyplex SuperBug CRE, BD MAX Check-Points CPO, ANd PCR Tests as Well as Inferred Phenotype Resistance For: ESBL-Positive AND CR ESCHERICHIA COLI IsOLATES $(N=140)$

\begin{tabular}{|c|c|c|c|}
\hline $\begin{array}{l}\text { Resistance mechanism } \\
\text { identified by } \\
\text { phenotypic methods } \\
\text { (no. of isolates) }\end{array}$ & $\begin{array}{c}\text { Resistance mechanism } \\
\text { identified by } \\
\text { eSBCRE test } \\
\text { (no. of isolates) }\end{array}$ & $\begin{array}{c}\text { Resistance mechanism } \\
\text { identified by } \\
\text { BD MAX }{ }^{\mathrm{TM}} \text { Check-Points } C P O \\
\text { test (no. of isolates) }\end{array}$ & $\begin{array}{c}\text { Resistance mechanism } \\
\text { identified by } \\
\text { PCR test } \\
\text { (no. of isolates) }\end{array}$ \\
\hline ESBL positive (84) & ESBL positive (86) & - & CTX-M positive (86) \\
\hline - & CTX-M1 group positive (76) & - & - \\
\hline - & CTX-M9 group positive $(10)^{\mathrm{b}}$ & - & - \\
\hline MBL positive $(15)^{\mathrm{a}}$ & VIM positive $(15)^{\mathrm{a}}$ & VIM/IMP positive (15) & VIM positive (15) \\
\hline OXA-48 likely (9) ${ }^{\mathrm{b}}$ & OXA-48 positive $(1)^{\mathrm{b}}$ & OXA-48 positive (1) & OXA-48 positive (1) \\
\hline
\end{tabular}

${ }^{a}$ Including one E. coli strain ESBL (0) and MBL positive (1) in the phenotypic methods and CTX-M1 group (1) and VIM positive (1) in the eSBCRE test.

${ }^{\mathrm{b}}$ Including one E. coli strain ESBL positive (0) and OXA-48 likely (1) in the phenotypic methods and CTX-M9 group (1) and OXA-48 positive (1) in the eSBCRE test.

CR, carbapenem-resistant; eSBCRE, eazyplex ${ }^{\circledR}$ SuperBug CRE; ESBL, extended-spectrum beta-lactamases; MBL, metallo-betalactamases; OXA-48, 48-oxacillinases; VIM, Verona integron-encoded metallo-beta-lactamase. 
hours, but it does not differentiate carbapenemases and sometimes false-negative results have been found, especially with mucoid Gram-negative isolates with a low carbapenemase activity. ${ }^{23}$

García-Fernández et al. ${ }^{24}$ analyzed 45 Enterobacterales isolates derived from clinical samples in which phenotypic resistance resulted from the carbapenemase production, with or without the presence of ESBL. Absolute concordance $(100 \%)$ was reported between the inferred phenotype and the eSBCRE test results. Furthermore, co-expressions of ESBLs with carbapenemases were identified.

In this study, 2 of $140 \mathrm{E}$. coli isolates were positive for both ESBL and carbapenemase genes with the eSBCRE, PCR, and real-time PCR assays, whereas they were negative in the DDST. The DDST is a phenotypic method that is cheap, sensitive, and easy to apply in routine laboratories; however, it is time-consuming, does not distinguish between the specific types of ESBL, and sometimes false-negative results are obtained with this test, especially, when ESBL is co-expressed with carbapenemase.

Among the phenotypic methods, unspecific results can also be found with the $30 \mu \mathrm{g}$ temocillin test for OXA-48. The temocillin test is known to be a very sensitive but not a very specific test for the detection of OXA-48. In this study, of $16 \mathrm{E}$. coli isolates positive in the Carba NP test, 9 were also positive for OXA-48 according to the $30 \mu \mathrm{g}$ temocillin test, which suggests the potential production of OXA-48 carbapenemase, whereas the gene encoding this type of carbapenemase was detected only in $1 \mathrm{E}$. coli isolate with the eSBCRE, PCR, and real-time PCR assays.

In this study, $100 \%$ concordant results between the PCR/ real-time PCR, and the eSBCRE assays were found. However, the eSBCRE test has some limitation; it does not detect the $b l a_{\text {IMP }}$ gene. It is not, however, of a great epidemiological significance, because the prevalence of the $b l a_{\text {IMP }}$ gene in Enterobacterales is low in Poland. None of the examined $E$. coli isolates were positive in terms of $b l a_{\mathrm{IMP}}$ genes.

Among all $E$. coli isolates, one gave invalid results in the form of a simultaneous fluorescent signal for all betalactamase genes. This phenomenon was also reported by other authors, ${ }^{8}$ who believe that it results from the massive release of DNA from bacterial cells that failed to be previously lysed during the incubation step. Extending the incubation time allows for the cell lysis and prevents false fluorescence signals.

The main factor limiting the widespread use of the eSBCRE is its high price compared with the prevalent microbiological culture-based techniques. Moreover, parallel antimicrobial-resistance testing may still be needed for betalactamase-producing MDR and XDR bacteria, owing to the need to choose an adequate antimicrobial therapy.

In summary, the eSBCRE test, based on LAMP method, is a reliable, easy-to-use, and timesaving molecular system. It can be successfully used in the routine microbiological diagnostic for the rapid detection of the most common ESBL and carbapenemase genes among clinical $E$. coli isolates. It allows to obtain results in a shorter time compared with phenotypic or even PCR, and real-time PCR methods. Moreover, the test is simple to implement and does not require optimization because of the possibility of using commercial tests.

The use of this test allows to make a decision on the implementation of patient contact isolation in a short time, which prevents from the dissemination of ESBL- and/or carbapenemase-positive Enterobacterales to other susceptible patients and also makes possible to exclude the patient's carrier without undue delay, and to avoid the prolongation of isolation time. Moreover, it enables to implement an adequate antimicrobial therapy as soon as possible, which may affect the patient's health or even life, making it clinically and epidemiologically useful.

\section{Disclosure Statement}

No competing financial interests exist.

\section{Funding Information}

This research was financially supported by the Collegium Medicum Nicolaus Copernicus University in Bydgoszcz, with funds from the maintenance of the research potential of the Department of Microbiology and funds from a minigrant for students' research projects.

\section{References}

1. Vila, J., E. Sáez-López, J.R. Johnson, U. Römling, U. Dobrindt, R. Cantón, C.G. Giske, T. Naas, A. Carattoli, M. Martínez-Medina, J. Bosch, P. Retamar, J. RodríguezBaño, F. Baquero, and S.M. Soto. 2016. Escherichia coli: an old friend with new tidings. FEMS Microbiol. Rev. 40: 437-463.

2. Grundmann, H., C. Glasner, B. Albiger, D.M. Aanensen, C.T. Tomlinson, A.T. Andrasević, R. Cantón, Y. Carmeli, A.W. Friedrich, C.G. Giske, Y. Glupczynski, M. Gniadkowski, D.M. Livermore, P. Nordmann, L. Poirel, G.M. Rossolini, H. Seifert, A. Vatopoulos, T. Walsh, N. Woodford, and D.L. Monnet. 2017. Occurrence of carbapenemase-producing Klebsiella pneumoniae and Escherichia coli in the European survey of carbapenemase-producing Enterobacteriaceae (EuSCAPE): a prospective, multinational study. Lancet Infect. Dis. 17:153-163.

3. Pitout, J.D., and K.B. Laupland. 2008. Extended-spectrum beta-lactamase-producing Enterobacteriaceae: an emerging public-health concern. Lancet Infect. Dis. 8:159-166.

4. Mokracka, J., A. Oszyńska, and A. Kaznowski. 2013. Increased frequency of integrons and $\beta$-lactamase-coding genes among extraintestinal Escherichia coli isolated with a 7-year interval. Antonie Van Leeuwenhoek 103:163-174.

5. Ojdana, D., P. Sacha, P. Wieczorek, S. Czaban, A. Michalska, J. Jaworowska, A. Jurczak, B. Poniatowski, and E. Tryniszewska. 2014. The occurrence of blaCTX-M, blaSHV, and blaTEM genes in extended spectrum $\beta$-lactamasepositive strains of Klebsiella pneumoniae, Escherichia coli and Proteus mirabilis in Poland. Int J Antibiot. 2014:1-7.

6. de Paz, H.D., P. Brotons, and C. Muñoz-Almagro. 2014. Molecular isothermal techniques for combating infectious diseases: towards low-cost point-of-care diagnostics. Expert Rev. Mol. Diagn. 14:827-843.

7. Findlay, J., K.L. Hopkins, D. Meunier, and N. Woodford. 2015. Evaluation of three commercial assays for rapid detection of genes encoding clinically relevant carbapenemases in cultured bacteria. J. Antimicrob. Chemother. 70: 1338-1342.

8. Hinić, V., J. Ziegler, C. Straub, D. Goldenberger, and R. Frei. 2015. Extended-spectrum $\beta$-lactamase (ESBL) detection directly from urine samples with the rapid isothermal amplification-based eazyplex ${ }^{\circledR}$ SuperBug CRE assay: proof of concept. J. Microbiol. Methods 119:203-205. 
9. Zboromyrska, Y., A. Vergara, C. Cosgaya, G. Verger, N. Mosqueda, M. Almela, C. Pitart, I. Roca, F. Marco, and J. Vila 2015. Rapid detection of $\beta$-lactamases directly from positive blood cultures using a loop-mediated isothermal amplification (LAMP)-based assay. Int. J. Antimicrob Agents 46:355-356.

10. Rödel, J., J.A. Bohnert, S. Stoll, L. Wassill, B. Edel, M. Karrasch, B. Löffler, and W. Pfister. 2017. Evaluation of loopmediated isothermal amplification for the rapid identification of bacteria and resistance determinants in positive blood cultures. Eur. J. Clin. Microbiol. Infect. Dis. 36:1033-1040.

11. European Committee on Antimicrobial Susceptibility Testing Breakpoint tables for interpretation of MICs and zone diameters Version 9.0. 2019. Available at http://eucast .org/fileadmin/src/media/PDFs/EUCAST_files/Breakpoint_ tables/v_9.0_Breakpoint_Tables.pdf

12. Nordmann, P., L. Poirel, and L. Dortet. 2012. Rapid detection of carbapenemase-producing Enterobacteriaceae. Emerg. Infect. Dis. 18:1503-1507.

13. Lee, K., Y.S. Lim, D. Yong, J.H. Yum, and Y. Chong. 2003. Evaluation of the Hodge test and the imipenemEDTA double-disk synergy test for differentiating metallobeta-lactamase producing isolates of Pseudomonas spp. and Acinetobacter spp. J. Clin. Microbiol. 41:4623-4629.

14. Doi, Y., B.A. Potoski, J.M. Adams-Haduch, H.E. Sidjabat, A.W. Pasculle, and D.L. Paterson. 2008. Simple disk-based method for detection of Klebsiella pneumoniae carbapenemasetype beta-lactamase by use of a boronic acid compound. J. Clin. Microbiol. 46:4083-4086.

15. Glupczynski, Y., T.D. Huang, W. Bouchahrouf, R. Rezende de Castro, C. Bauraing, M. Gérard, A.M. Verbruggen, A. Deplano, O. Denis, and P. Bogaerts. 2012. Rapid emergence and spread of OXA-48-producing carbapenemresistant Enterobacteriaceae isolates in Belgian hospitals. Int. J. Antimicrob. Agents 39:168-172.

16. van Dijk, K., G. Voets, J. Scharringa, S. Voskuil, A.C. Fluit, W.C. Rottier, M.A. Leverstein-Van Hall, and J.W. Cohen Stuart. 2014. A disc diffusion assay for detection of class A, B and OXA-48 carbapenemases in Enterobacteriaceae using phenyl boronic acid, dipicolinic acid, and temocillin. Clin. Microbiol. Infect. 20:345-349.

17. Magiorakos, A.P., A. Srinivasan, R.B. Carey, Y. Carmeli, M.E. Falagas, C.G. Giske, S. Harbarth, J.F. Hindler, G. Kahlmeter, B. Olsson-Liljequist, D.L. Paterson, L.B. Rice, J. Stelling, M.J. Struelens, A. Vatopoulos, J.T. Weber, and D.L. Monnet. 2012. Multidrug-resistant, extensively drugresistant and pandrug-resistant bacteria: an international expert proposal for interim standard definitions for acquired resistance. Clin. Microbiol. Infect. 18:268-281.
18. Liao, K., Y. Chen, M. Wang, P. Guo, Q. Yang, Y. Ni, Y. Yu, B. Hu, Z. Sun, W. Huang, Y. Wang, A. Wu, X. Feng, Y. Luo, Z. Hu, Y. Chu, S. Chen, B. Cao, J. Su, B. Gui, Q. Duan, S. Zhang, H. Shao, H. Kong, and Y. Xu. 2017. Molecular characteristics of extended-spectrum $\beta$-lactamase-producing Escherichia coli and Klebsiella pneumoniae causing intraabdominal infections from 9 tertiary hospitals in China. Diagn. Microbiol. Infect. Dis. 87:45-48.

19. Pitout, J.D., D.B. Gregson, L. Poirel, J.A. McClure, P. Le, and D.L. Church. 2005. Detection of Pseudomonas aeruginosa producing metallo-beta-lactamases in a large centralized laboratory. J. Clin. Microbiol. 43:3129-3135.

20. Poirel, L., C. Héritier, V. Tolün, and P. Nordmann. 2004. Emergence of oxacillinase-mediated resistance to imipenem in Klebsiella pneumoniae. Antimicrob. Agents Chemother. 48:15-22.

21. Akova, M., G.L. Daikos, L. Tzouvelekis, and Y. Carmeli. 2012. Interventional strategies and current clinical experience with carbapenemase-producing Gram-negative bacteria. Clin. Microbiol. Infect.18:439-448.

22. Nordmann, P., and L. Poirel. 2014. The difficult-tocontrol spread of carbapenemase producers among Enterobacteriaceae worldwide. Clin. Microbiol, Infect. 20: 821-830.

23. Tijet, N., D. Boyd, S.N. Patel, M.R. Mulvey, and R.G. Melano. 2013. Evaluation of the Carba NP test for rapid detection of carbapenemase-producing Enterobacteriaceae and Pseudomonas aeruginosa. Antimicrob. Agents Chemother. 57: 4578-4580.

24. García-Fernández, S., M.I. Morosini, F. Marco, D. Gijón, A. Vergara, J. Vila, P. Ruiz-Garbajosa, and R. Cantón. 2015. Evaluation of the eazyplex ${ }^{\circledR}$ SuperBug CRE system for rapid detection of carbapenemases and ESBLs in clinical Enterobacteriaceae isolates recovered at two Spanish hospitals. J. Antimicrob. Chemother. 70:1047-1050.

Address correspondence to: Patrycja Zalas-Wiecek, PhD Department of Microbiology Ludwik Rydygier Collegium Medicum Nicolaus Copernicus University

Dr Antoni Jurasz University Hospital No. 1 9M. Sktodowska-Curie Street Bydgoszcz 85094 Poland

E-mail: patrycjazalas@go2.pl 